\title{
EFFECT OF TAMSULOSIN ON TREATMENT OF LOWER URETERIC CALCULI
}

\author{
RAHMAN MM ${ }^{1}$, JOHURA FT ${ }^{2}$, ALI MI ${ }^{3}$ HOSSAIN MS ${ }^{4}$, ISLAM MK ${ }^{5}$
}

\begin{abstract}
Introduction: Medical expulsive therapy (MET) is one of the treatment modality for ureteric calculi. Recent studies have reported excellent results with MET for lower ureteral calculi. The aim of study to evaluate the effect of tamsulosin on treatment of lower ureteric calculi.

Materials and Methods: A prospective study was conducted at outpatient department of Urology, Prime Medical College Hospital, Rangpur, Bangladesh during February 2018 to February 2019. A total of 100 patients with lower ureteric calculi included in this study. Cases were selected by inclusion and exclusion criteria and randomly allocated in two groups. Tamsulosin group (50 patients) were given capsule tamsulosin $0.4 \mathrm{mg}$, at bed time while observation group (50 patients) were given standard therapy without tamsulosin. The patients were prescribed diclofenac $(50 \mathrm{mg})$ on demand for pain relief and were followed-up by $X$ ray and ultrasonography of kidney, ureter and urinary bladder region for 28 days. The stone expulsion rate, expulsion time, and analgesic requirements were also recorded. Data were analyzed and compared by statistical tests.
\end{abstract}

Results: Tamsulosin group showed a statistically significant advantage in terms of the stone expulsion rate. A stone expulsion rate of $78 \%$ (39 out of 50 patients) in tamsulosin group and $54 \%$ (27 out of 50 patients) was observed for observation group ( $\mathrm{p}=0.011)$. In tamsulosin group, mean expulsion time was $7.26 \pm 3.35$ days whereas in observation group mean expulsion time of $8.93 \pm 3.56$ days $(\mathrm{p}=0.017)$. Tamsulosin group stone expulsion time was lower as compared to observation group. Overall the number of doses of analgesic (diclofenac) required in tamsulosin group, it was $3.78 \pm 2.82$ whereas in observation group was observed to be $5.93 \pm 1.76$. The variation between number of doses of analgesic required by patients in both groups was found to statistically significant $(\mathrm{p}=0.001)$.

Conclusions: The effectiveness of tamsulosin as a medical expulsive therapy in patients with lower ureteric calculi was higher as compared to observation group. Tamsulosin has been found to increase stone expulsion rates, reduces mean days to stone expulsion and decreases number of doses of analgesic requirement.

Key Words: Medical expulsive therapy (MET), Tamsulosin, lower ureteral calculi.

Bangladesh J. Urol. 2019; 22(2): 155-159

1. *Dr.Md. Mostafiger Rahman, Assistant Professor, department of Urology, Prime Medical College, Rangpur

2. Dr. Fatema-Tui-Johura, Assistant Professor, department of Pharmacology, Prime Medical College, Rangpur

3. Dr. Mohammad Ibrahim Ali, MS (Urology). Indoor Medical Officer, department of Urology, Dhaka Medical College, Dhaka.

4. Dr. Md. Sazzad Hossain. MS (urology) Registrar. Apollo Hospital Itd. Ghulsan, Dhaka

5. Dr. Md. Kamrul Islam, MS (Urology), Medical Officer, Zila Sadar Hospital,Hobigong.

Address of correspondence: Dr. Md. Mostafiger Rahman, Assistant Professor, Department of Urology, Prime Medical College, Rangpur, Bangladesh. mostafiger.bd@gmail.com; Mobile: +8801717 137953

Received: 05 February 2019

Accepted: 10 May 2019
Introduction:

Urinary stone disease is one of the most common reasons for patients visiting a urology practice, affecting about $5 \%$ to $10 \%$ of the population[1]. Among all ureteral stones, $70 \%$ are found in the lower third of the ureter[2]. Symptoms include flank or abdominal pain radiating to the groin or external genitalia. Although some patients with ureteral stones might remain asymptomatic, many have pain and thus commonly seek medical care. An acute episode of colic is the result of a stone entering the ureter and causing intermittent rise of pressure in 
the pyelocalyceal system. Spontaneous passage of stone will occur in most of them are $<4 \mathrm{~mm}$ in size and lower down in the ureter[3]. Treatments for ureteric stones traditionally include watchful waiting, extracorporeal shock wave lithotripsy, ureteroscopy and open ureterolithotomy[4]. The goal of the surgical treatment of patients suffering from ureteral calculi is to achieve complete stone clearance with minimal morbidity[5]. According to the European Association of Urology (EAU) and the American Urologic Association (AUA) joint Guideline for the Management of Ureteral Calculi, patients with a newly diagnosed ureteral stone $<10 \mathrm{~mm}$ and whose symptoms are controlled, observation with periodic evaluation is an option for initial treatment[6,7]. Such patients may be offered an appropriate medical expulsive therapy (MET) to facilitate stone passage during the observation period[6]. Stone size and location are the main factors that can influence their passage; a stone smaller than $4 \mathrm{~mm}$ is usually passed after conservative treatment[8]. Different modalities of medical expulsive therapy have been evaluated, including alpha-blockers, calcium channel blockers, corticosteroids and combinations of aforementioned[2,9]. Medical expulsive therapy is an appropriate treatment modality for lower ureteric calculi in terms of stone expulsion and control of ureteral colic pain and most studies have been performed with alphablockers[2,3,10]. Recently, a á1A receptor blocker to be used in this regard is tamsulosin. Alpha-blockers tend to decrease intra-ureteral pressure and increase fluid passage which might increase stone passage. Effective medical expulsive therapy has several potential benefits. MET would decrease the duration of symptoms of ureteral stones and therefore the rate of complications such as urinary tract infections (UTI), hydronephrosis and kidney function impairment. It would potentially decrease the use of more invasive interventions such as ESWL and ureteroscopy and therefore decrease the rate of possible complications of these procedures. Last, it would likely spare limited health-care resources, such as physician time and hospital beds[3]. The most important advancement in the treatment of distal ureteric calculi in recent year has been the discovery of role of medical expulsive therapy to facilitate spontaneous expulsion of small ureteric calculi[10]. The aim of present study was carried out to evaluate the efficacy of Tamsulosin on treatment of lower ureteral calculi.

\section{Materials and Methods}

A prospective study was conducted in the outpatient department of Urology of Prime Medical College
Hospital, Rangpur, Bangladesh between February 2018 to February 2019. This study was approved by the Ethical Review Committee, Prime Medical College, Rangpur, Bangladesh. Written informed consent was taken from every case. A total of 100 patients older than 18 years of age, presenting with a diagnosis of a symptomatic, unilateral, solitary unimpacted lower ureteral stones proved either on a Xray or sonography of the KUB (Kidney-Ureter- Bladder) or intravenous urography with size $\geq 4 \mathrm{~mm}$ and $\leq 10 \mathrm{~mm}$ (in major axis) were included in this study. There are no change or mild fullness or mild dilatation of the pelvicalyceal system at the stone side also included in this study. A lower ureteric stone was located in pelvic cavity from below the lower border of the sacroiliac joint to at the level of ischial spine or ureteric orifice. All cases having active urinary tract infection, fever, acute renal failure, chronic renal failure, history of urinary surgery or endoscopic treatment, stones in the upper or middle ureter; marked back pressure effect of affected side, bilateral stones, diabetes mellitus, gastric or duodenal ulcer, known sensitivity to $\beta$ blockers, concomitant treatment with á blockers, $\beta$ blockers, calcium antagonist, pregnancy, history of spontaneous stone expulsion, known ureteral stricture and kidney or ureteral abnormalities (e.g. single kidney, ureteral malformation) were excluded from the study.

Prior to study, complete blood count, serum creatinine, urine RME \& culture sensitivity, X-ray KUB and USG of KUB or intravenous urography were carried out on all patients. Patients were randomly allocated in to two groups; Tamsulosin group (50 patients) were given capsule tamsulosin $0.4 \mathrm{mg}$, at bed time while observation group (50 patients) were given standard therapy without tamsulosin. All patients were advised to standard therapy consisted of appropriate hydration (to have high fluid intake more than three liters a day) and the use of analgesic (Diclofenac $50 \mathrm{mg}$ on demand), with or without prophylactic antibiotics. Patients were evaluated every seven days using the results of physical examination, ultrasonography of KUB and X-ray of KUB was performed on days 14 and 28. Final evaluation was done after completion of 28 days. Patients were instructed to note the time and the date of expulsion of stone. Successful stone expulsion was defined as complete passage of stone as evidenced by patient was confirmed by Xray or USG of KUB within 28 days or earlier. Failure was considered if the patient failed to pass the stone at the end of 28 days or uncontrolled pain and /or uroseptic fever to 
patient. The stone expulsion rate, expulsion time, number of doses of analgesic requirements were also recorded. For data analysis Microsoft excel and statistical software SPSS was used and data was analyzed with the help of frequencies, figures, proportions, measures of central tendency, appropriate statistical test wherever required. The $p$-value $<0.05$ was considered significant.

\section{Results}

This study titled effect of tamsulosin on treatment of lower ureteric calculi performed in 100 patients. Tamsulosin group patients were given cap tamsulosin $(0.4 \mathrm{mg})$ while observation group patients were given standard therapy. Mean ages of the patients in the observation and tamsulosin groups were $40.30 \pm 15.9$, and $36.00 \pm 12.22$ years respectively $(p=0.1327)$. The male to female ratio were $1.58: 1$ and $1.65: 1$ for observation and tamsulosin group respectively. There was no side predominance in any of the groups. The mean stone size was $6.28 \pm 1.83$ for tamsulosin and $6.38 \pm 1.25$ for observation group $(p=0.7504)$. There was no statistical significant difference in age, gender and stone size distribution between the two groups. A stone expulsion rate of $78 \%$ (39 out of 50 patients) in tamsulosin group and $54 \%$ (27 out of 50 patients) was observed for observation group. Tamsulosin group showed a statistically significant advantage in terms of the stone expulsion rate $(p=0.011)$. According to stone expulsion time in tamsulosin group, mean expulsion time was $7.26 \pm 3.35$ days whereas in observation group had mean expulsion time of $8.93 \pm 3.56$ days $(p=0.017)$. Overall the number of doses of analgesic (diclofenac) required in tamsulosin group it was $3.78 \pm 2.82$ whereas in observation group was observed to be $5.93 \pm 1.76$. The variation between doses required by patients in both groups was found to statistically not significant $(p=0.001)$.

Table-I

Comparison of various characteristics of both groups

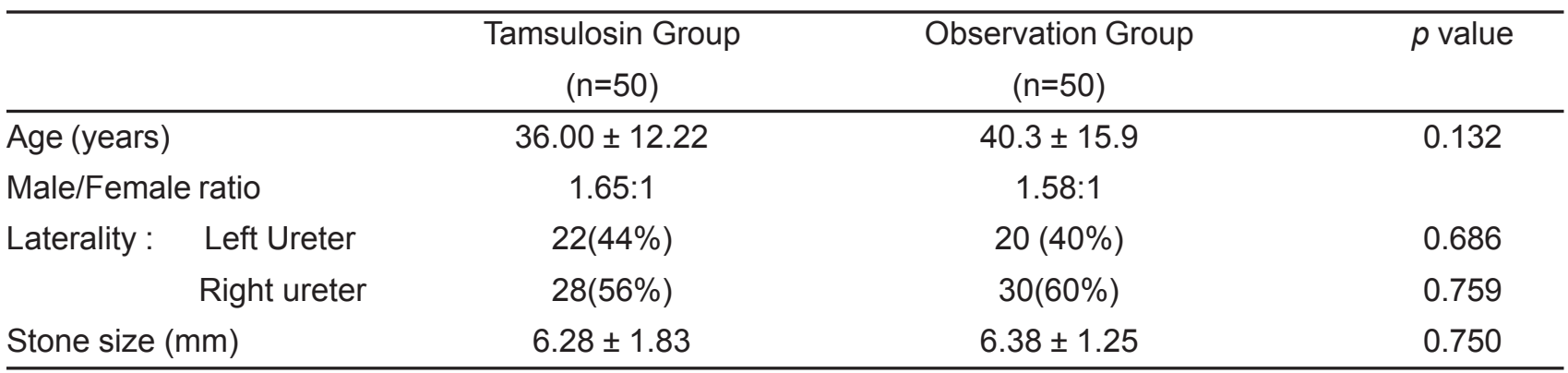

Table-II

Effect of tamsulosin on Stone expulsion rate

\begin{tabular}{lccc}
\hline Stone Expulsion rate & $\begin{array}{c}\text { Tamsulosin Group } \\
(\mathrm{n}=50)\end{array}$ & $\begin{array}{c}\text { Observation Group } \\
(\mathrm{n}=50)\end{array}$ & $p$ value \\
\hline Yes & $39(78 \%)$ & $27(54 \%)$ & 0.011 \\
No & $11(22 \%)$ & $23(46 \%)$ & \\
\hline
\end{tabular}

Table-III

Effect of tamsulosin on stone expulsion time and analgesic requirements

\begin{tabular}{lccc}
\hline & $\begin{array}{c}\text { Tamsulosin Group } \\
(\mathrm{n}=50)\end{array}$ & $\begin{array}{c}\text { Observation Group } \\
(\mathrm{n}=50)\end{array}$ & $p$ value \\
\hline Expulsion Time (days) & $7.26 \pm 3.35$ & $8.93 \pm 3.56$ & 0.017 \\
Analgesic requirements (No. dose) & $3.78 \pm 2.82$ & $5.93 \pm 1.76$ & 0.001 \\
\hline
\end{tabular}




\section{Discussion}

Various treatment options are available for the management of distal ureteral calculi. Tamsulosin is a safe and effective drug that enhances spontaneous passage of distal ureteral stones sized less than 10 $\mathrm{mm}[11]$. Cervenàkov et al[12] demonstrated that standard treatment was supplemented by the administration of the alpha-1 blocker Tamsulosin, helped to accelerate the passing of minor calculi from the terminal parts of the ureters of $80.4 \%$ of patients. Selective alpha-blockers have a crucial impact in spontaneous painless elimination of the stones smaller than $8 \mathrm{~mm}$ located in the uretero-bladder junction[13]. In present study, the mean stone size was $6.38 \pm 1.25$ for control group and $6.28 \pm 1.83$ for tamsulosin group $(p=0.7504)$. Dellabella $\mathrm{M}$ et al observed in their study that mean stone size in two groups was 5.8 and 6.7 $\mathrm{mm}(p=0.001)$ [4]. Ahmed $\mathrm{H}$ et al reported mean stone size to be $5.78 \mathrm{~mm}$ (range $4-8 \mathrm{~mm}$ ) in greatest dimension[14]. Ureteral stones less than $10 \mathrm{~mm}$ treated with alpha-receptor antagonists compared to placebo[3]. In present study, a stone expulsion rate of $54 \%$ (27 out of 50 patients) was observed for control group and $78 \%$ (39 out of 50 patients) in tamsulosin group $(p=0.0117)$. Abdulla- al Ansari et al, reported 100 cases of distal ureteric stones where the stone expulsion occurred in 41 of 50 patients $(82 \%)$ in group with MET and in 28 of 46 patients $(61 \%)$ in placebo group $(p=0.02)$ [15]. Ferre MR et al found in their study that successful spontaneous stone expulsion at 14 days was similar between the groups, with $27(77.1 \%)$ subjects in the tamsulosin group and 24 (64.9\%) subjects in the standard therapy group, a difference of $12 \%(95 \% \mathrm{Cl}-8.4 \%$ to 32.8$)$ [16]. The stone-free rate favored alpha-blockers in solely distal ureteral stones (RR1.44, 95\% Cl 1.29 to $1.60, \mathrm{P}<0.00001 ; \mathrm{I}^{2}=66 \%$ )[3]. The expulsion rate was found to be higher for tamsulosin, followed by nifedipine and phloroglucinol; the expulsion rates were $97.1 \%$ and $77.1 \%, 64.3 \%$, respectively[4]. A 2014 Cochrane review on medical expulsive therapy with a-blockers concluded that they resulted in higher stone-free rates and a shorter time to stone expulsion[3] Cervenakov et al demonstrated forty-one of the 51 (80.4\%) receiving tamsulosin passed their stones spontaneously as compared to $32(62.8 \%)$ in the other cohort. Time to passage was also more expeditious in the tamsulosin group[12]. In the current study, according to stone expulsion time in control group had mean expulsion time of $8.93 \pm 3.56$ days, whereas in tamsulosin group; mean expulsion time was 7.26 \pm 3.35 days $(p=0.017$ ). Mohammed AB et al found in their study that the average time to expulsion was $12.53 \pm 2.12$ days for group A (control group) and $7.32 \pm 0.78$ days for group $B$ (tamsulosin group) $(p=0.04)$ [17]. Dellabella $M$ et al observed in their study that mean expulsion time was 111.1 hours for control group and 65.7 hours for tamsulosin group $(p=0.020)$ [4]. De Sio et al published a study of 96 patients and achieved $90 \%$ expulsion rate with tamsulosin therapy[18]. MS Griwan et al, noticed overall stone expulsion rate of 21 out of 30 patients ( $70 \%$ ) was observed for control group and 27 out of 30 patients (90\%) in study group[19]. In present study, number of dose of analgesic (diclofenac) dosage required in control group was observed to be $3.78 \pm 2.82$ whereas in tamsulosin group it was $5.93 \pm$ $1.76 ;(p=0.001)$. Gupta $G$ et al observed stone free rate were higher in tamsulosin group and less number of times use of diclofenac as well as less time to expulsion of fragments were prominent findings of study[20]. Dellabella M et al observed in their study that the mean number of diclofenac injections was 2.83 for group 1 and 0.13 for group $2(p<0.0001)$ [4]. A randomized controlled trial by Dellabella and associates demonstrated that tamsulosin may be effective in facilitating the passage of distal ureteral calculi[4]. Tamsulosin is beneficial in terms of clearance of lower ureteral stones and this effect was more evident for larger stones, especially when combined with shock wave lithotripsy (SWL) [21]. Dellabella et al, used tamsulosin as a spasmolytic drug during episodes of ureteral colic due to juxtavesical calculi, observed an increased stone expulsion rate and with a decrease in stone expulsion time, the need for hospitalization and endoscopic procedures, and provided particularly good control of colic pain. ${ }^{4}$ In this study tamsulosin has been found to increase stone expulsion rates, reduces mean days to stone expulsion in lower ureteric calculi. Since this is a single centre study, a multi centre study at a larger scale is required.

\section{Conclusions:}

The effectiveness of tamsulosin as a medical expulsive therapy in patients with lower ureteric calculi was higher as compared to observation group.

\section{Limitations of the Study}

It was a single center study with relative small sample size and all complications of MET were not included in the study.

\section{Conflicts of Interest}

The authors declare no conflicts of interest regarding the publication of this paper. 
Sciences. $2014 ; 1(2): 19-22$

\section{References}

1. Ramello A, Vitale C, Marangella M. Epidemiology of nephrolithiasis. Journal of Nephrology 2000; 13 Suppl 3: S45-50. [MEDLINE: 11132032]

2. Hollings worth JM, Rogers MAM, Kaufman SR. Medical therapy to facilitate urinary stone passage: a metaanalysis. Lancet. 2006; 368:1171-9.

3. Campschroer T, Zhu X, Vernooij RWM, Lock MTWT. Alpha blockers as medical expulsive therapy for ureteral stones. Cochrane Database of Systematic Reviews 2018, Issue 4. Art. No.: CD008509. DOI: 10.1002/ 14651858.CD008509.pub3.

4. Dellabella M, Milanese G, Muzzonigro G Efficacy of tamsulosin in the medical management of juxtavesical ureteral stones. J Urol .2003; 170: 2202-2205.

5. Lingeman JE, Matlaga BR, Evan AP. Surgical management of upper urinary tract calculi. In: Kavoussi LR, Novick AC, Partin AW, Peters AC, Wein AJ, eds. Campbell-Walsh urology. Saunders Elsevier: Philadelphia; 2007:1431-1507.

6. Preminger GM, Tiselius H-G, Assimos DG, et al. Guideline for the management of ureteral calculi. J Urol. 2007; 178:2418-2434.

7. Türk C, Petrík A, Sarica K, et al. EAU guidelines on diagnosis and conservative management of urolithiasis. Eur Urol. 2016; 69:468-474.

8. Dellabella M, Milanese G, Muzzonigro G Efficacy of tamsulosin in the medical management of juxtavesical ureteral stones. J Urol .2003; 170: 2202-2205.

9. Singh A, Alter HJ, Littlepage A. A systematic review of medical therapy for facilitate passage of ureteral calculi. Annals of Emergency Medicine 2007; 50(5):552-63. [MEDLINE: 17681643]

10. Wolf JS Jr. Treatment selection and outcomes: Ureteral calculi. Urol Clin N Am 2007; 34:428-32.

11. Narayan Thapa, Bhandari BB, Hamal BK. Tamsulosin in the management of distal ureteric calculi, Journal of Patan Academy of Health
12. Cervenakov I, Fillo J, Mardaik J, Kopency M, Smilrala J, Lepies. Speedy elimination of urolithiasis in lower part of ureters with alpha1 blockers tamsulosin. Int J Urol Nephrol. 2002; 34:25-9.

13. Pricop C, Novac C, Negru D, liie C, Pricop A, Tanase A. Can selective alpha blockers help the spontaneous passage of the stones located in the uretero bladder junction? Rev Med ChirSoc Med Nat. 2004; 108:128-33.

14. Ahmad H, Azim W, Akmal M, Murtaza B, Mahmood A, Nadim A, et al. Medical expulsive treatment of distal ureteral stone using tamsulosin. J Ayub Med Coll Abbottabad. 2015 27 (1):4850.

15. Al-Ansari A, Al-Naimi A, Al Obaidy A, Assadiq K, Azim MD, Shokoir A, et al. Efficacy of tamsulosin in the Management of Lower Ureteral Stones: A Randomized Double-blind Placebo-controlled Study of 100 Patients. Urology. 2009; 09:73.

16. Ferre M, Jessica MW, Tania DS. Tamsulosin for ureteral stones in the emergency department: a randomized, controlled trial. Ann Emerg Med. 2009; 54(3):432-9.

17. Sayed MAB, Abolyosr A, Abdalla MA, El-Azab AS. Efficacy of tamsulosin in medical expulsive therapy for distal ureteral calculi. Scandinavian J Urol Nephrol. 2008;42(1)

18. De sio M, Antorino R, Di Lorenzo G, Damiano R, Giardono D, Consentino K, et al. medical expulsive treatment of distal-ureteral stones using tamsulosin: a single center experience. J endourol. 2006; 20:12-6.

19. Griwan MS, Singh SK, Paul H, Pawar BS, Verma $M$, et al. The efficacy of tamsulosin in lower ureteral calculi. Urol Ann. 2010 May-Aug; 2(2): 63-6.

20. Gupta G, Aswathaman K, Kekre NS. Does tamsulosin facilitate expulsion of distal ureteric calculus following lithotripsy? Indian J Urol. 2008 24 (2):274-5.

21. Kupeli B, Irkilata L, Gurocak S, Tun CL, Kirac M, Karaoglan V, et al. Does tamsulosin enhance lower ureteral stone clearance with or without shock wave lithotripsy? Urology 2004; 64:1111-5. 